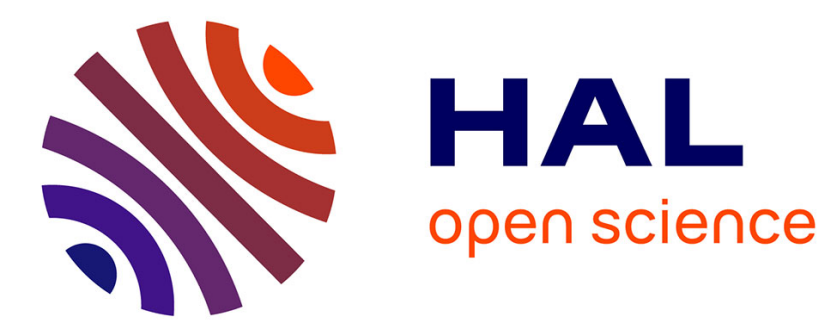

\title{
GRAIN BOUNDARY STRUCTURE AND MECHANICAL PROPERTIES OF THE TiAl INTERMETALLIC COMPOUND
}

\author{
R. Imayev, G. Salishchev
}

\section{- To cite this version:}

R. Imayev, G. Salishchev. GRAIN BOUNDARY STRUCTURE AND MECHANICAL PROPERTIES OF THE TiAl INTERMETALLIC COMPOUND. Journal de Physique Colloques, 1990, 51 (C1), pp.C1-519-C1-524. 10.1051/jphyscol:1990181 . jpa-00230349

HAL Id: jpa-00230349

https://hal.science/jpa-00230349

Submitted on 1 Jan 1990

HAL is a multi-disciplinary open access archive for the deposit and dissemination of scientific research documents, whether they are published or not. The documents may come from teaching and research institutions in France or abroad, or from public or private research centers.
L'archive ouverte pluridisciplinaire HAL, est destinée au dépôt et à la diffusion de documents scientifiques de niveau recherche, publiés ou non, émanant des établissements d'enseignement et de recherche français ou étrangers, des laboratoires publics ou privés. 
COLLOQUE DE PHYSIQUE

Colloque C1, supplément au $n^{\circ} 1$, Tome 51, janvier 1990

\title{
GRAIN BOUNDARY STRUCTURE AND MECHANICAL PROPERTIES OF THE TIAI INTERMETALIIC COMPOUND
}

\author{
R.M. IMAYEV and G.A. SALISHCHEV \\ Institute of Metals Superplasticity Problems, URSS Academy of Sciences, \\ Ufa 45000I, U.R.S.S:
}

\begin{abstract}
Résumé - L'étude des propriétés mécaniques du composé intermétallique TiAl a été faite de la température ambiante à $1050^{\circ} \mathrm{C}$. Ces propriétés dépendent fortement de la structure des joints de grain. En particulier, le comportement mécanique du composé intermétallique est relié à la capacité des joints à absorber les dislocations.
\end{abstract}

\begin{abstract}
An investigation of the TiAl intermetallic compound mechanical properties has been undertaken in the temperature interval of $20-1050^{\circ} \mathrm{C}$. Its properties have been found to be considerably dependent on the structure of grain boundaries. Absorption properties of grain boundaries and mechanical behaviour of the intermetallic material are shown to be interrelated.
\end{abstract}

\section{1 - INTRODUCTION}

Presently, grain boundaries are undoubtedly recognized to be the most important component of a polycrystal structure exerting considerable influence on the mechanical properties of polycrystals /1-5/. At the same time, it is evident that these properties depend not only on the length of $\mathrm{GB}$, but also on their structure /5-7/. This paper presents experimental data which prove that grain boundary structure and properties should be taken into account when predicting mechanical behaviour of polycrystals.

The TiAl intermetallic compound (superlattice $L_{10}$ ) was specially chosen as an object for investigacion. This alloy is brittle and strain-resistant even at high temperatures /8, $9 /$. However, when converted to a fine-grained state, it can display superplasticity (SP) in certain temperature-rate conditions of deformation /10/. This material was chosen to enable a special kind of experiment with the end of comparing the alloy mechanical properties in states with close grain sizes, but considerably different in their GB structures /11, 12/.

2 - MATERIAL AND EXPERIMENTAL PROCEDURE

The Ti-36 wt\% Al alloy (further denoted as TiAl) in the form of ingots and blanks obtained by the compaction of granules was used. The required structural states were created by means of special treatment whose modes are given in the Table.

Table. Modes of the TiAl Alloy Treatment.

\begin{tabular}{cl} 
State & \multicolumn{1}{c}{ Modes of Treatment } \\
\hline I & $\begin{array}{l}80 \% \text { hot compression straining of the compacted alloy at } 1000^{\circ} \mathrm{C} \text { and at the strain } \\
\text { rate of } 10^{-3} \mathrm{~s}-1\end{array}$ \\
II & Same as in $\mathrm{I}+$ annealing at $1050^{\circ} \mathrm{C}$ for 2 hours \\
II & Same as in I, but for the cast alloy $+70 \%$ restraining under the same conditions \\
& and with a change of the direction of deformacion to $90^{\circ}$ \\
IV & Sane as in III, but the restraining takes place at $1100^{\circ} \mathrm{C}$ \\
V & Same as in III + annealing at $1050^{\circ} \mathrm{C}$ for 2 hours
\end{tabular}

Mechanical tensile tests were conducted on the Ingtron machine in the temperature interval of $20-1050^{\circ} \mathrm{C}$ at the initial strain rate of $8.3 \times 10^{-4} \mathrm{~s}$. At $1025^{\circ} \mathrm{C}$ tests were conducted at the initial strain rates of $(1.6-8.3) \times 10^{-4} \mathrm{~s}^{-1}$.

Tensile diagrans were used to define: maximal relative elongation to rupture, $\delta$; true flow stress at the relative elongation of $50 \%, \sigma_{50}$ conditional temporal resistance, $\sigma_{t}$. The strain rate sensitivity coefficient, $m$, was evaluated by the slope of $1 \mathrm{~g} \sigma 0^{-1 g} \dot{\varepsilon}$ curves. For mechanical tosts flat specimens with the working portion dimensions of $10^{0} \times 5 \times 2$ mn were used. 
These specimens were prepared by grinding with subsequent electropolishing.

To know the absorption properties of GB, the temperature of relaxation, $t$, i.e. "blurring" of electron microscopic contrast, of trapped lattice dislocations (TLD) in' GB was measured. To do this, the alloy specimens in states IV and $V$ after $2.5 \%$ deformation at room temperature were annealed for 15 minutes at various temperatures.

3 -RESULTS

3.1 Superplastisity of TiAl.

States I and II were studied.

Mechanical properties. The temperature dependence of the alloy mechanical properties in state I is as follows. With the rise of testing temperature the relative elongation to rupture, $\delta$, first gradually grows, but after the maximum (250\%) has been reached at $1025^{\circ} \mathrm{C}$, it abruptly decreases. Flow stress decreases monotonously with the rise of temperature.

Flow stress, $\sigma_{50}$, largely depends on the strain rate at $1025^{\circ} \mathrm{C}$ (Fig. $1 \mathrm{a}$ ), the strain rate sensitivity of $\sigma_{50}$ in state $I$, contrary to state $I I$, in a certain strain rate interval being increased.
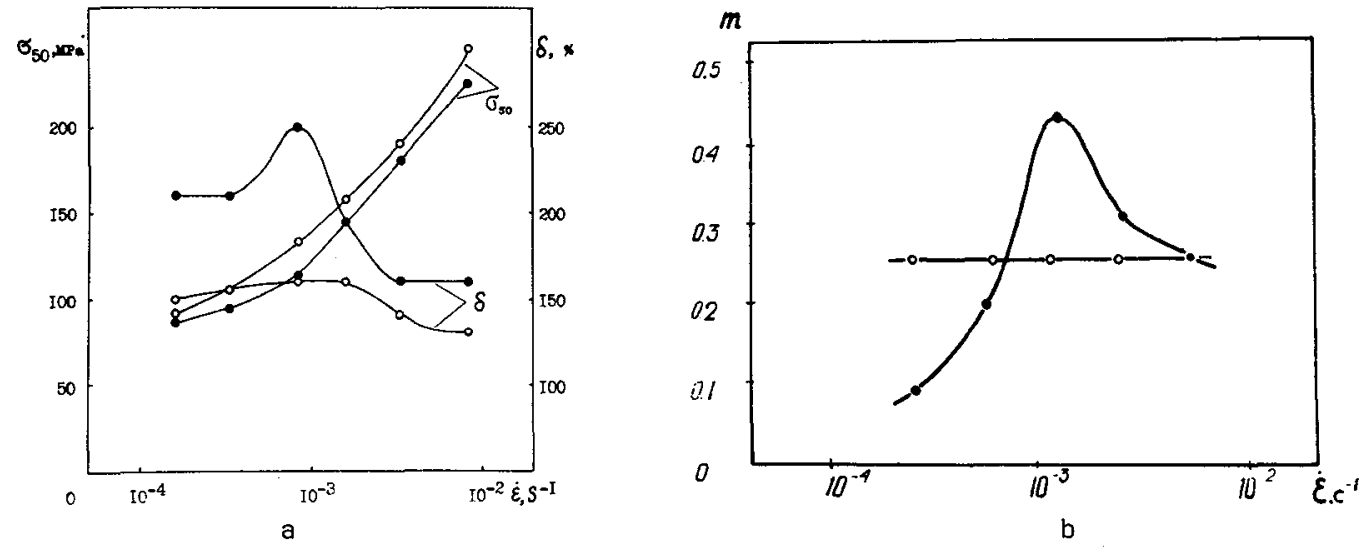

Fig. 1 - The effect of strain rate on the TiAl mechanical properties: - state I; o state II $\left(t=1025^{\circ} \mathrm{C}\right)$

Thus, for state $I$ the $m$ values in the strain rate interval of $(0.83-1.6) \times 10^{-3} \mathrm{~s}^{-1}$ vary rrom 0.33 to 0.43 (Fig. 1b). Higher values of $\mathrm{m}$ are matched with the largest relative elongations to rupture (200-250\%). For state II, $m$ is constant throughout the considered strain rate interval and its value is 0.26 and relative elongation only slightly depends on strain rate $(\delta=130-160 \%)$.

Thus, in state I the alloy displays SP features while in state II SP behaviour is less pronounced.

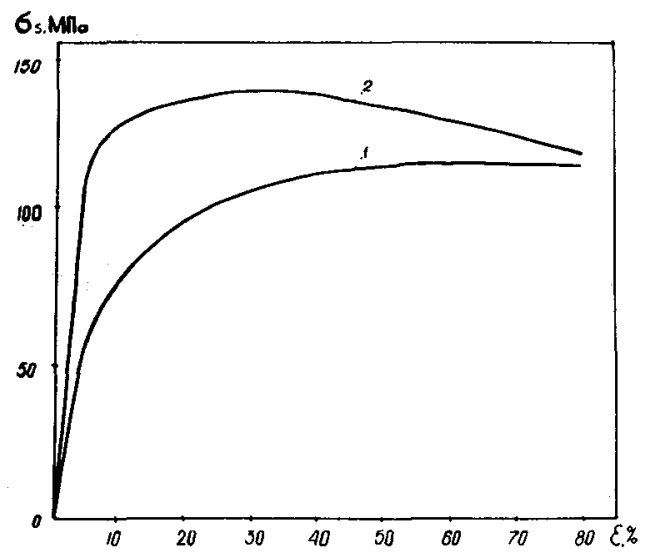

Fig. 2 - The flow-stress-deformation curves or the TiAl alloy in states I (1) and II (2) $\left(t=1025^{\circ} \mathrm{C}\right.$, strain rate $\left.8.3 \times 10^{-4} \mathrm{~s}^{-1}\right)$ 
Fig. 2 shows $\sigma_{s}-\varepsilon$ curves during the tensile straining of the alloy specimens in states $I$ and II at an optimal strain rate. ${ }^{S}$ The stage of steady state flow is preceded by a prolonged stage of strengthening. In state II at the initial stage, the $\sigma$ peak is observed. With further deformation the flow stress monotonously decreases and approaches the $\sigma_{s}$ level in state $I$.

Microstructure. When specimens are heated up to the optimal temperature of $1025^{\circ} \mathrm{C}$ their mean grain size $d$ in state I increases from 5 to $8 \mu \mathrm{m}$. Subsequent soaking at this temperature for five hours causes no further growth of $\bar{d}$. In state $\mathrm{II}$, microstructure at $1025^{\circ} \mathrm{C}$ is stable with $\bar{d}=9.5 \mu \mathrm{m}$.
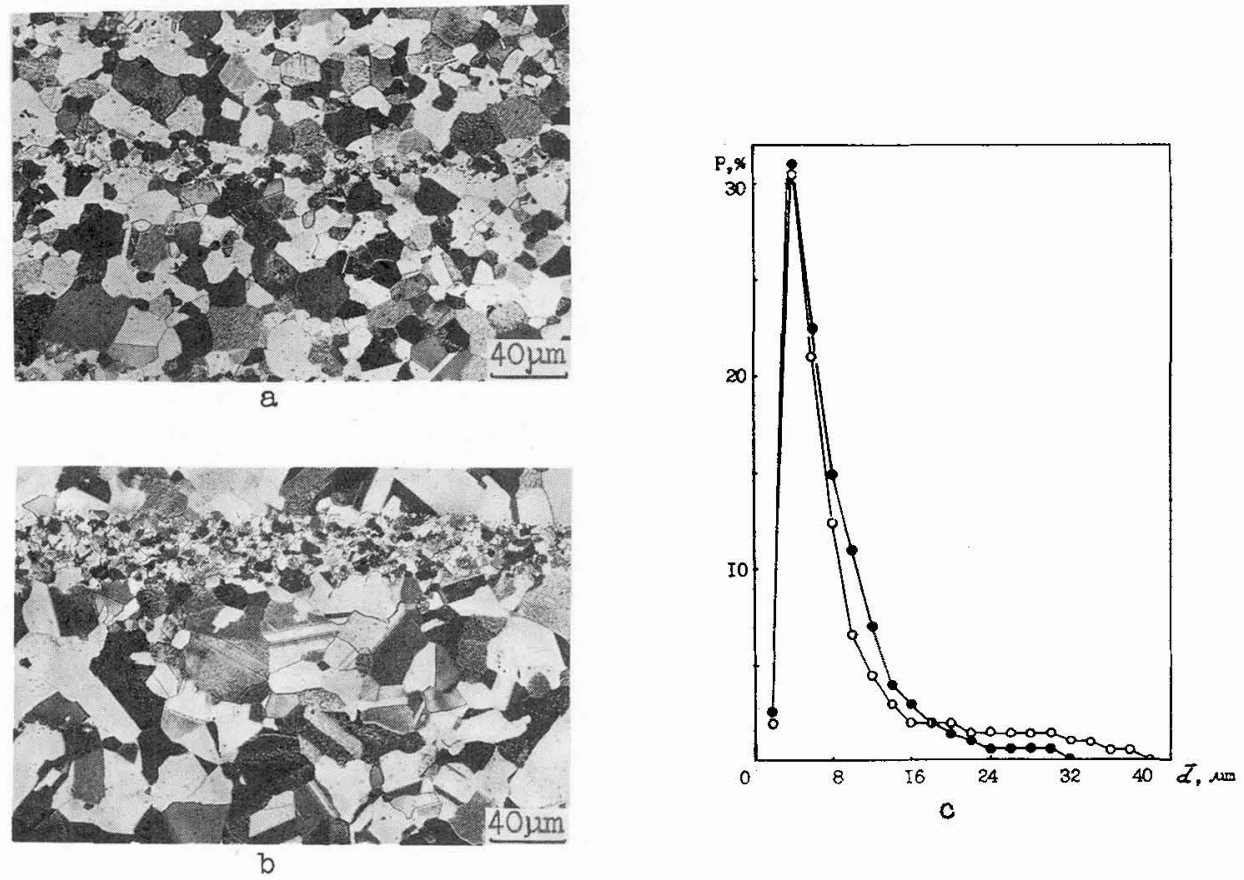

Fig. 3 - Microstructure and histograms of grain size distribution of the TiAl alloy in the head of specimens $160 \%$ deformed at $1025^{\circ} \mathrm{C}$ and $\dot{\varepsilon}=8.3 \times 10^{-4} \mathrm{~s}^{-1}$ : a - state I; b - state II; c: - state I, o - state II.

Fig. 3 shows the microstructure and histograms of the grain size distribution in both states in specimen heads. Besides the main $\gamma$-phase (TiAl) the alloy also contains about 3 vol.\% of $\alpha_{2}$-phase ( $\mathrm{Ti}_{3} \mathrm{Al}$ - superlattice $\mathrm{DO}_{19}$ ) in the form of particles sized $0.1-3 \mu \mathrm{m}$ located mainly in GB. No difference in the amount, distribution, size, and shape of the $\alpha$-phase particles is observed. Comparison of the grain size distribution histograms of the alloy states shows that they are practically identical. Twin boundaries are observed in the microstructure of the alloy states. Their fraction in states I and II is 10 and $35 \%$ respectively of the total number of grains. No $\alpha_{2}$-particles are observed in twin boundaries. Since states I and II are characterized by close grain sizes, similar amount, shape, size, and distribution of $\alpha_{2}$-phase particles, the difference of the alloy properties in the said states are obviously due to the structure of GB, $i$.e. different number of twin boundaries in each state.

3.2 Tough-brittle transition in TiAl.

States III-V were studied.

Microstructure. Fig. 4 shows the microstructure and histograms of grain size distribution of the states. There are no differences in the amount, distribution, sizes, and shape of the $\alpha$ phase particles either. The mean grain size is $5 \mu \mathrm{m}$ in state III, $9 \mu \mathrm{m}$ in state IV, $11 \mu \mathrm{m}$ in state $V$. The comparison of grain size distribution histograms in states III and IV has shown that they are practically identical. Annealing twins are observed in the microstructure of the states. Most of them are in state five making about $50 \%$ of boundaries while in states III and IV the fraction of twin boundaries does not exceed $5 \%$. No $\alpha_{2}$-phase particles precipitate in
twin boundaries.

Mechanical properties. Mechanical properties of the alloy in states III-V are shown in Fig.5. The dependence of conditional temporal resistance, $\sigma_{+}$, on temperature for all the states is of an anomalous character. With the rise of temperatưre $\sigma_{t}$ increases reaching the maximum at 

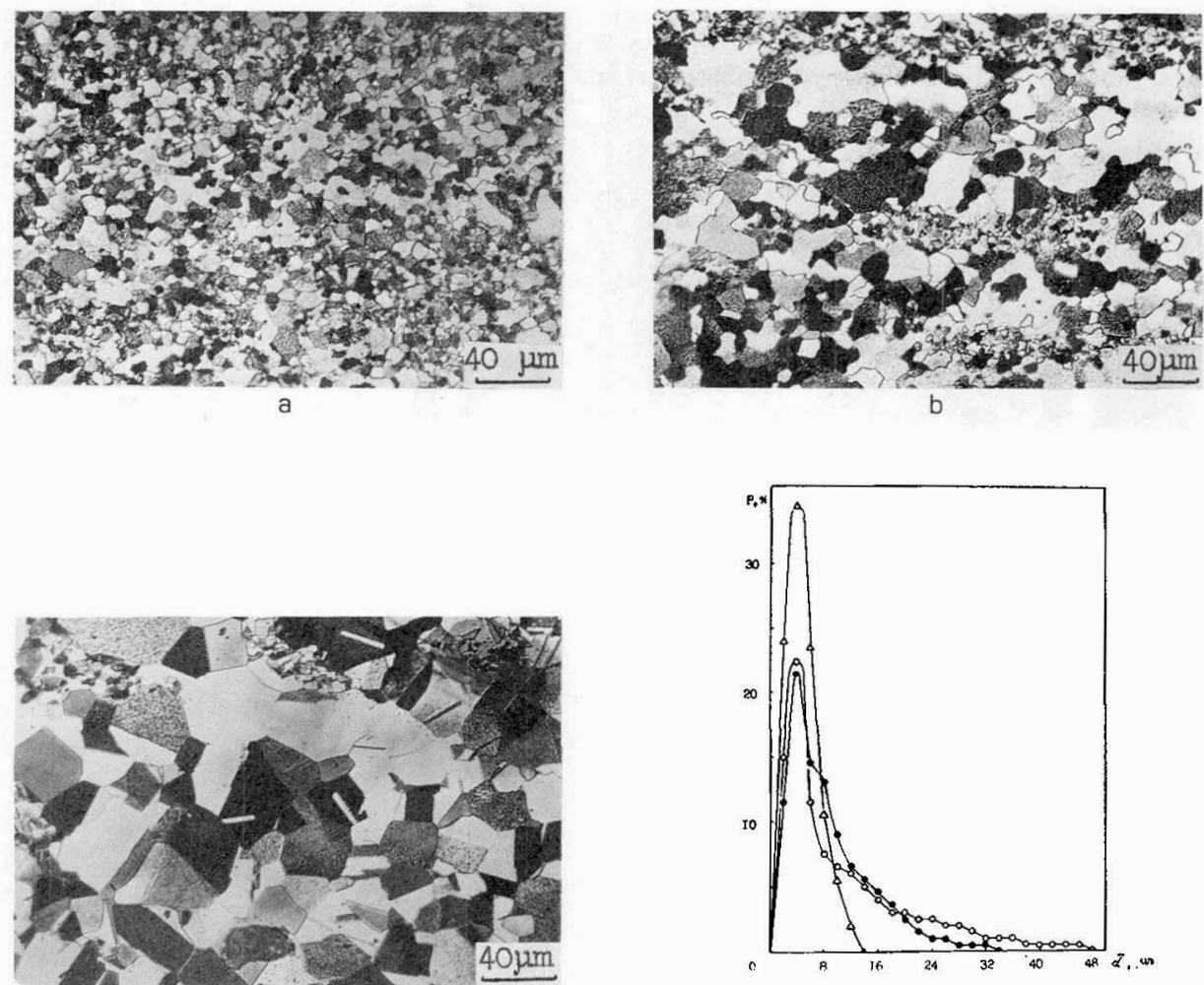

d

Fig. 4 - Microstructures and histograms of the grain size distribution of the TiAl alloy: a - state III; b - state IV; c: $\Delta$ - state III, - state IV, o - state V.

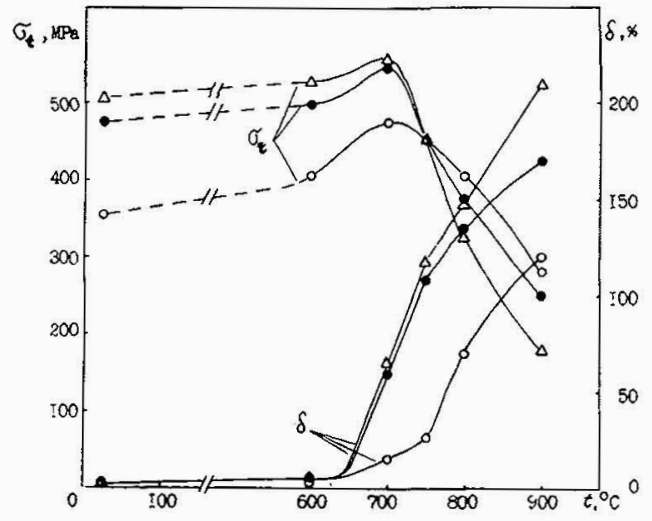

Fig. 5 - TiAl mechanical properties: $\Delta$ - state III, - state IV, o - stae V.

$750^{\circ} \mathrm{C}$, but with the further rise of temperature it decreases. In the same temperature interval where $\sigma$ increases, the growth of $\delta$ takes place indicating that the tough brittle transition (TBT) $\mathrm{t}_{\text {is in in progress. }}$

The original microstructure influences the alloy properties which depend to a greater extent 
on the GB structure than on the grain size. Thus, for example, states III and IV being considerably different in grain sizes, have practically identical properties. At the same time if we take states IV and $V$, the difference in their properties is connected with the difference in the GB structure since grain sizes in these states are quite close. States III and IV are are characterized by higher values of $\delta$ and $\sigma_{t}$ as compared to state $V$. Only at $t>750^{\circ} \mathrm{C}, \sigma_{t}$ for state $V$ is higher than in states III and IV,

Absorption properties of GB. The study of the relaxation of TLD in GB during annealing shows that in twin boundaries contrast due to TLD does not disappear even after the annealing at $1100^{\circ} \mathrm{C}$ (Fig. 6a). At $1000^{\circ} \mathrm{C}$ and more the TLD system in twin boundaries becomes ordered forming quasiperiodical rows and nets. Other boundaries which are obviously random are deprived of TLD already at $600^{\circ} \mathrm{C}$ (Fig. 6b).
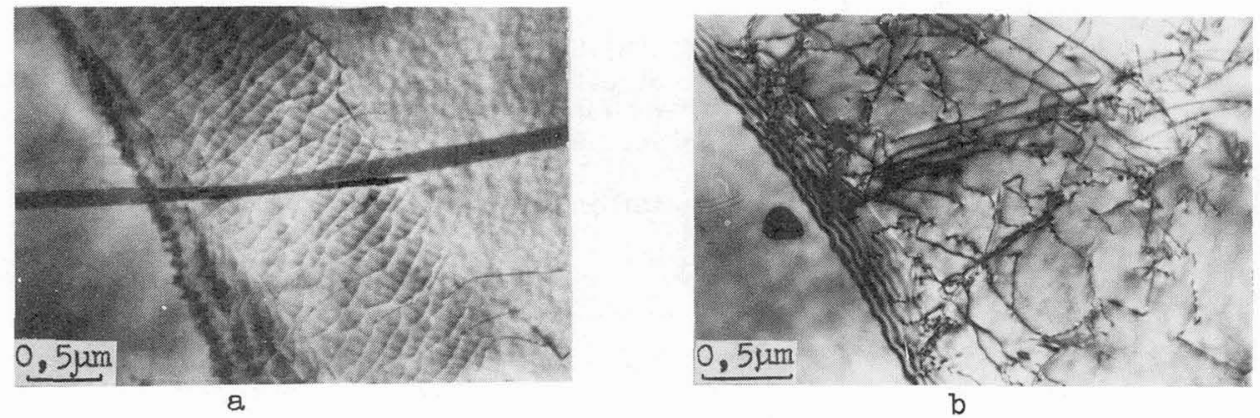

Fig. 6 - The relaxation of TLD in GB: a - $t_{a n n}=1100^{\circ} \mathrm{C}$, twin boundary; b $-600^{\circ} \mathrm{C}, 15$ minutes

Results obtained during the study of TLD relaxation in GB allow to define the fraction of twin and random boundaries in states IV and $V$ of the alloy. It was established that the fraction of twin boundaries in these states constitutes 3 and $50 \%$ respectively, the rest being random boundaries. Hence, these results agree with those obtained metallographically.

4 - DISCUSSION

In the TBT interval and the SP conditions the TiAl mechanical properties depend to a great extent on the structure of GB. The growth of the fraction of twin boundaries leads to a considerable increase of the alloy plasticity above $600^{\circ} \mathrm{C}$.

With the rise of temperature the ability of GB to absorb dislocations becomes very important for the growth of polycrystal plasticity /4, 5/. The study of the absorption properties of GB has shown that twin boundaries are less efficient as sinks for dislocations than random boundaries. That is why the growth of their fraction in the alloy leads to the decrease of its plasticity in the TBT interval above $600^{\circ} \mathrm{C}$. Under the SP conditions, according to the model of grain boundary dislocation '(GBD) motion kinetics, GB act not only as sinks for dislocations, but also as a "channel" along which plastic deformation is effectuated through the motion of GBD $/ 13 /$.

Since during. the SP flow grain boundary sliding in twin boundaries is impeded due to a low mobility of GBD in these boundaries $/ 4,5 /$, the increase of their fraction in the alloy leads to the decrease of the alloy plasticity under the given condition.

According to the experiment, the TLD relaxation in random boundaries occurs at temperatures which are lower than those of TBT. At the same time the process of TLD relaxation in GB is known $/ 4,5 /$ to be indicative of the snhanced mobility of GBD in the boundaries. Hence, the growth of the TiAl plasticity in the polycrystalline state with the rise of temperature in the TBT interval is related to the enhancement of the GBD mobility in GB.

\section{5 - CONCLUSIONS}

1. Mechanical properties of the TiAl intermetallic compound are largely dependent on the: structure of grain boundaries. The growth of the fraction of twin boundaries in the alloy considerably decreases its plasticity at temperatures above $600^{\circ} \mathrm{C}$.

2. The relaxation of TLD in TiAl occurs at temperatures which are lower than those of TBT. 
12/ Grabski, M. W., Grain Boundary Structure in Metals. Moscow, Metallurgia Publ., 1972(in Rus.) /3/ Orlov, A. K., Perevezentsev, V. N., and Rybin, V. V., Grain Boundaries in Metals. Moscow, Metallungia Publ., 1980 (in Russian).

14/ Kaibyshev, 0. A., Superplasticity of Commercial Alloys. Moscow, Metallurgia Publ., 1984 (in Russian).

15/ Kaibyshev, 0. A., Valiev, R. Z., Grain Boundaries and Properties or Metals. Moscow, Metallurgia Publ., 1987 (in Russian).

/6/ Watanabe, T., Res Mechanica 115 (1984) 47.

17/ Valiev, R. Z., Zelin, M. G., and Sergeev, V. I., Fizika Metallov i Metallovedenie (FMM) 60 (1985) 980 (in Russian).

18/ Altunin, YU. F. and Glazunov, S. G. In: Titanium in Industry. Moscow, Oborongiz, 1961 (in Russian).

19) Teitel, E. I., Yakovleva, E. S., and Kozlov, V. G., Tekhnologia Legkikh Splavov, No 2 (1977) 35 (in Russian).

110/ Kaibyshev, 0. A., Czech. J. Phys. B38 (1988) 395.

/11/ Imayev, R. M. and Salishchev, G. A. in: Structure and Properties of Internal Interfaces in Metals and Semiconductors. Varonezh, 1988 (in Russian).

112/ Kaibyshev, 0. A., Salishchev, G. A., Imayev, R. M., and Kotkin, A. B., FMM 65 (1987) 998 (in Russian).

/13/ Kaibyshev, 0. A., Valiev, R. Z., and Emaletdinov, A. K., phys. stat. sol. (a) 90 (1985) 197 . 